\title{
Article \\ Electroencephalography (EEG)-Based Neural Emotional Response to the Vegetation Density and Integrated Sound Environment in a Green Space
}

\author{
Chengcheng Zeng ${ }^{1,+}{ }^{\oplus}$, Wei Lin ${ }^{2,+}$, Nian Li ${ }^{1}$, Ya Wen ${ }^{1}$, Yanxin Wang ${ }^{1}$, Wenyuan Jiang ${ }^{1}$, Jialing Zhang ${ }^{1}$, \\ Haolin Zhong ${ }^{1}$, Xin Chen ${ }^{1}$, Wenhao Luo ${ }^{1}$ and Qibing Chen ${ }^{1, *}$ \\ 1 College of Landscape Architecture, Sichuan Agricultural University, Chengdu 611130, China; \\ zcclandscape@163.com (C.Z.); nli@sicau.edu.cn (N.L.); wenyasc@163.com (Y.W.); wyeah725@163.com (Y.W.); \\ cheungyuan070@126.com (W.J.); coconut0320@126.com (J.Z.); zbaklu530723633@gmail.com (H.Z.); \\ djx583304937@163.com (X.C.); robinlwh0927@163.com (W.L.) \\ 2 College of Landscape Architecture, Zhejiang A \& F University, Hangzhou 311300, China; \\ landscape1990@163.com \\ * Correspondence: cqb@sicau.edu.cn; Tel.: +86-028-8265-2175 \\ + Co-first author.
}

check for

updates

Citation: Zeng, C.; Lin, W.; Li, N.; Wen, Y.; Wang, Y.; Jiang, W.; Zhang, J.; Zhong, H.; Chen, X.; Luo, W.; et al. Electroencephalography (EEG)-Based Neural Emotional Response to the Vegetation Density and Integrated Sound Environment in a Green Space. Forests 2021, 12, 1380. https:// doi.org/10.3390/f12101380

Academic Editor: David Hladnik

Received: 18 September 2021

Accepted: 7 October 2021

Published: 10 October 2021

Publisher's Note: MDPI stays neutral with regard to jurisdictional claims in published maps and institutional affiliations.

Copyright: (C) 2021 by the authors. Licensee MDPI, Basel, Switzerland. This article is an open access article distributed under the terms and conditions of the Creative Commons Attribution (CC BY) license (https:// creativecommons.org/licenses/by/ $4.0 /)$.

\begin{abstract}
Emotion plays an important role in physical and mental health. Green space is an environment conducive to physical and mental recovery and influences human emotions through visual and auditory stimulation. Both the visual environment and sound environment of a green space are important factors affecting its quality. Most of the previous relevant studies have focused solely on the visual or sound environment of green spaces and its impacts. This study focused on the combination of vegetation density (VD) and integrated sound environment (ISE) based on neural emotional evaluation criteria. VD was used as the visual variable, with three levels: high $(\mathrm{H})$, moderate $(\mathrm{M})$ and low (L). ISE was used as the sound variable, with four levels: low-decibel natural and low-decibel artificial sounds (LL), low-decibel natural and high-decibel artificial sounds (LH), high-decibel natural and low-decibel artificial sounds (HL) and high-decibel natural and highdecibel artificial sounds $(\mathrm{HH})$. These two variables were combined into 12 unique groups. A total of 360 volunteer college students were recruited and randomly assigned to the 12 groups $(\mathrm{N}=30)$. All 12 groups underwent the same $5 \mathrm{~min}$ high-pressure learning task (pretest baseline), followed by a 5 min audio-visual recovery (posttest). Six indicators of neural emotion (engagement, excitement, focus, interest, relaxation and stress) were dynamically measured by an Emotiv EPOC X device during the pretest and posttest. Analysis of covariance was used to determine the main and coupled effects of the variables. (1) VD and ISE have significant effects on human neural emotions. In moderate- and high-VD spaces, artificial sound levels may have a positive effect on excitement. (2) A higher VD is more likely to result in excitatory neural emotion expression. (3) Low-VD and high-VD spaces have a higher degree of visual continuity. Both extremely low and extremely high VDs result in a higher expression of stressful emotions than observed for a moderate VD. (4) High-decibel artificial sounds are more likely to attract attention, possibly because artificial sounds are easier to recognize than natural sounds. However, when both the natural and artificial sounds are low, it is difficult to induce higher tones, and the lower the artificial sound decibel level, the easier it is to relax. Additionally, under the influence of an ISE, attention recovery and stress recovery may be negatively correlated. The results show that an appropriate combination of VD and ISE can improve the health benefits of a green space and thus the well-being of visitors.
\end{abstract}

Keywords: green space; vegetation density; integrated sound environment; EEG; neural emotion 


\section{Introduction}

\subsection{Background}

Global urbanization has led to a decrease in the frequency of human contact with the natural environment [1], which may affect health and well-being. In recent years, young people have had the highest proportion of health problems among the population [2]. Emotions are the physiological and psychological reactions of human beings and play an important role in human cognition [3,4]. They are commonly associated with logical decision making, perception, and human interaction. Emotions can be both positive and negative, and they affect human health and productivity. Ekman [5] believed that humans are born with emotions and exhibit similar physical behavior when expressing the same emotions. Emotions play a very important role in our daily lives, but scientific knowledge related to emotions is still very limited. As a natural environment, green space is increasingly considered a way to improve urban public health, and it is often linked to theories of stress, mental fatigue, restoration and the induction of positive emotions [6]. In his theory of attention recovery, Kaplan [7] proposed that the natural environment helps to improve attention. Uhich [8] studied architectural spaces with and without vegetation and noted that people have positive physiological and psychological responses to environments with vegetation. Green space improves the physical and mental health of residents, who benefit via increased attention, reduced stress and anxiety, fatigue recovery, improved mood levels and increased well-being [9-11]. Peter [12] demonstrated in a walking experiment that green space is an environment that improves emotions and that people who enter a green space experience lower frustration and higher engagement and excitement. Moreover, numerous studies have proved that improving the green space can be used as an adjunctive therapy without side effects to promote patients' disease cure and physical rehabilitation, especially in hospitals and living spaces [13]. Several studies have summarized that green space has three general functions: harm reduction (e.g., reducing air pollution, noise and heat), resilience (e.g., restoring attention and physical stress) and capacity building (e.g., encouraging physical activity and promoting social cohesion). Air quality, physical activity, social contact and stress are four ways to produce health effects on humans [6,14].

\subsection{Electroencephalography (EEG)-Based Neural Emotion}

In affective neuroscience, emotion is often thought of as a diffuse emotional state [15]. Facial expressions are one of the most direct ways in which humans communicate emotions and intentions [16]. Psychologists can distinguish among physiological arousal, behavioral expression and emotionally conscious experiences. It has been suggested that facial information and voice information are related to only behavioral performance that can be consciously controlled and modified; however, this suggestion is a subjective interpretation. In addition, emotions are not always shown through facial expressions. We need more in scientific evidence to study emotions. As a result, other methods of detecting emotions have been developed, including considering physiological information such as heart rate, skin conductance and pupil dilation [17]. In recent years, with the progress of science and technology, research on neural emotions in human-computer interactions has been increasing. Electroencephalography (EEG) is thought to be a physiological cue in which the electrical activity of nerve cells accumulates in the human cerebral cortex.

Six neural emotional indicators (engagement, excitation, focus, interest, relaxation and stress) can be output through an EEG device. In the study by Lin et al., six neural emotional parameters were provided by the Emotiv.

EPOC+ device were used to compare the differences between walking and sitting in green spaces, indicating the feasibility of neural emotional parameters [18]. They record brain activity in real time and convert varying frequencies of brain waves from multiple brain regions into intuitive neural emotions [19]. Because emotional indicators are relatively objective compared with nonphysical cues, EEG is reliable for emotional recognition [20]. In addition, EEG is considered a noninvasive method that allows the related experimentation to include a large number of nonclinical subjects. Chang et al. [21] explored the restorative 
effect of urban green space experience by using mobile electroencephalography (MOE) devices to measure brain waves, the results of which were used to describe attention $[21,22]$. Additionally, they used quantitative EEG to investigate different levels of biodiversity; they found that temperate deciduous broad-leaved forest habitats induced higher brain activity under the theta frequency of low biodiversity.

\subsection{Vegetation Density (VD) and the Integrated Sound Environment (ISE)}

Different combinations of elements in green spaces form different landscape environments and biodiversity. Vegetation density (VD) is usually considered an important factor. VD affects not only the plant community structure and forest canopy density but also the main space of human recreation and activities. Studies [23] have found that VD affects people's preference for natural landscapes. Another study by Jiang [24] also confirms this, showing that a slight increase in VD produces a sharp increase in preference. Purcell \& Lamb [23] found that different heights of vegetation $(10-30 \mathrm{~m})$ were significantly correlated with people's perception of nature. VD also affects the health benefits of natural landscapes. Grinde B [25] suggested that a visual lack of plants can have a negative impact on people's lives. Bjerke [26] suggested that different VDs have different effects on human mental and physical health. In addition, VD was used to predict the recovery effect of the natural environment based on people's preferences. Some studies have suggested that the relationship between VD and human preferences and health benefits is nonlinear [27,28].

As defined in ISO 12913-1, the acoustic environment consists of all sounds from all sources as modified by the environment (International Organization for Standardization, Geneva, Switzerland, 2014). The sound environment of green space can be mainly divided into two parts: natural sound sources and non-natural sound sources. Green spaces provide opportunities for people to get in touch with nature, but recreational activities result in unnatural sounds; both natural and artificial sounds can be perceived. Natural sound sources are related to the biodiversity and VD inside the green space, while non-natural sound sources are related to the city outside and the visitors within the green space. In this study, we combine these sound sources and name this combination the integrated acoustic environment (ISE). Psychoacoustic studies have often shown a relationship between the sound level (L), as measured in $\mathrm{dB}$, and the perceived loudness of pure tones, and the perceived loudness of pure tones doubles with every $10 \mathrm{~dB}$ increment [29]. The natural sound level is one of the key factors in the ISE and an important acoustic design factor that has been found to affect the perceived pleasantness of soundscapes as a key acoustic factor [30]. The decibel level of sound may be another key factor in people's perception of green spaces [31]. Aletta F summarized methods for assessing and measuring sound landscapes. It is also common to characterize the acoustic environment through psychoacoustic indicators such as loudness, sharpness, roughness, and fluctuation strength [32]. Many studies have shown that introducing pleasant natural sounds such as bird songs reduces the perceived loudness of existing noise sources and increases the pleasantness of a soundscape. In particular, congruency between the acoustic and visual environments is known to modulate audio-visual interactions, strongly affecting the appraisal of both soundscapes [33]. A recent study [34] using virtual reality to investigate the effects of sound on perceived and recreational value showed that the sound type changed people's perceived recreational value as the environment changed. A study of sonic landscapes in American national parks [35] showed that people visiting national parks had different sensitivities to artificial sounds in different areas. The more sensitive the areas were to artificial sounds, the more peaceful and isolated the people felt. The louder the artificial sounds (such as aircraft noises) were, the more agitated people felt. Studies [36] have shown that different sound types may have different degrees of perceptual impact on people. Focusing on the decibel level of sound, studies [37] have shown a link between noise thresholds and visitor capacity, with different noise thresholds being set to determine the number of visitors that can be accepted. In the prediction of the quietness of wilderness areas, the British scholar Watts P [38] tested the perception of soundscapes in the visual environment 
through both visual and sound stimulation and reflected on the current landscape feature evaluation model in the UK. He suggested that in landscape evaluation, not only the visual evaluation mode but also the relationship between the soundscape and landscape should be considered. Studies have shown that a sound environment can affect visual perception pathways. Providing sound that meets expectations can enhance subjects' visual evaluation of the outdoor environment, and appropriate sound can enhance the visual reality of simulation [39]. Other studies have also demonstrated the importance of sound in perceiving real or photographic environments, which can enhance or weaken visual representation and overall environmental evaluation [40,41]. In a study of national parks, it was found that sound affected not only the visual perception of the natural environment and the quiet space but also the performance of the sound barriers [38]. On the other hand, visual information can also affect the perception of the sound environment [33,42]. Moreover, in a study of landscape preferences, the effect of soundscapes was greater than that of visual landscapes [29]. However, Jeon and Jo [43] found the opposite result. In a study of nine locations in Seoul, South Korea, the impact of visual and audio information on overall urban environmental satisfaction was accounted for $76 \%$ and $24 \%$ of the total impact, respectively. Therefore, there are still many unknown interactive relationships between vision and hearing in green spaces that need to be studied.

\subsection{Objective and Expectations}

Previous research in this area has shown that the VD can be used to predict the benefits of nature or people's preferences for recovery [26]. At the same time, the ISE of a green space is also an important influencing factor and may have some relationship with VD to jointly affect human emotions. The purpose of this study is to explore the effects of different green space VDs and ISEs on human neural emotions. Based on previous studies using EEG devices [44] and taking other studies into consideration, we propose the following expectations: (1) a higher-decibel natural sound source will result in more favorable neural emotions; (2) a moderate level of VD will result in more favorable neural emotions; and (3) the most favorable neural emotions will be induced when a moderate level of VD is combined with higher natural tones.

\section{Materials and Methods}

2.1. Site

The experiment was divided into two stages: the pressure pretest and the recovery posttest. The participants were placed in a classroom on the campus of Sichuan Agricultural University, China. The classroom had windows (10 m long, $10 \mathrm{~m}$ wide and $4 \mathrm{~m}$ high) on the south side, and the curtains were closed during the experiment to avoid interference from the environment outside the window. The room was well ventilated and kept quiet at all times to ensure that the participants were protected from outside interference. The experiment took place in March 2021, between 8:00 a.m. and 12:00 p.m., between 1:00 p.m. and 5:00 p.m. and between 6:00 p.m. and 9:00 p.m. The indoor temperature, humidity and wind speed were maintained at $20-25{ }^{\circ} \mathrm{C}, 52-68 \%$ and $0 \mathrm{~m} / \mathrm{s}$, respectively.

\subsection{Participants}

We recruited 360 student volunteers ( $45 \%$ male and $55 \%$ female) by putting up posters on campus. The mean age of the participants was 21.5 years ( 18 to 26 years, $\mathrm{SD}=1.87$ ), and the body mass index (BMI), hearing and vision of each participant were within the normal range. None of the participants smoked or had a history of mental illness, and before the trial began, all participants were given full information about the study and voluntarily provided informed consent.

\subsection{Variables and Groups}

We adopted simulated pictures and sound, proposed four sound modes and three VD modes, and constructed 12 visual-acoustic combination forms. Photoshop was used to 
create an image of each experimental green space, including a path and vegetation. VD was one of the variables, and three levels (relative levels) were considered: high $(\mathrm{H})$, moderate (M) and low (L). The other variable was the ISE. The acoustic environment in this study was measured on the basis of the "noise level" index. The "noise level" is the A-weighted sound pressure, referred to as the "A-weighted sound pressure level". The "sound level" was measured with a noise meter (CEN-TER322). The overall sound level of the green space was determined by using the equivalent sound pressure level as an indicator, which was determined by the natural sounds (birds, animals, wind, leaves, streams and waterfalls) and artificial sounds (walking, talking, vehicles and aircraft). Based on the modes of high-decibel sound $(>65 \mathrm{~dB})$ and low-decibel sound $(<45 \mathrm{~dB})$, the comprehensive acoustic environment was divided into four levels: low-decibel natural and low-decibel artificial sounds (LL), low-decibel natural and high-decibel artificial sounds (LH), high-decibel natural and low-decibel artificial sounds (HL) and high-decibel natural and high-decibel artificial sounds $(\mathrm{HH})$. The two variables were combined into 12 groups: H-LL, H-LH, H-HL, H-HH, M-LL, M-LH, M-HL, M-HH, L-LL, L-LH, L-HL and L-HH.

\subsection{Measurement}

We used an Emotiv EPOC X EEG headset to capture the EEG signals. The device is nonintrusive and has the advantage of multichannel acquisition. Its 14 electrodes (AF3, AF4, F3, F4, F7, F8, FC5, FC6, T7, T8, P7, P8, O1 and O2) cover four brain lobes (frontal cortex, temporal cortex, parietal cortex and occipital cortex). The accuracy of the device has been confirmed in previous studies $[45,46]$. The brainwave data collected by the electrodes were sent to a computer's hard drive via Bluetooth. The EEG activity was then analyzed, and performance metric data containing six emotional indicators were output (engagement, excitation, focus, interest, relaxation and stress). The device outputs mood readings six times per minute.

\subsection{Procedure}

All subjects were randomly assigned to one of 12 groups. Each subject was led to the test area of the classroom wearing the EEG device. All the subjects performed the same 5 min high-pressure task as a pretest; the equipment had a baseline alignment time of $40 \mathrm{~s}$ before starting the test. The first part of the task involved advanced mathematical calculations far more difficult than college standards [47-49]. The subjects were asked to solve the mathematical calculations quickly, a process that put them under increased stress. The EEG device picked up brainwave data during the entire process and transmitted the data to a hard disk. The posttest consisted of viewing a green space image and listening to sounds. Before starting the posttest, we reconfirmed that the EEG equipment was operating normally. The subjects were required to sit in a fixed position and look at the pictures; they could not leave. After the $5 \mathrm{~min}$ posttest, the whole process was completed, and the total time was controlled to within 15 min (Figure 1).

We used the pretest (pressure induced stimulation) as a covariate and VD and the ISE as independent variables, and analysis of covariance (ANCOVA) was used to analyze the main effects (the pretest, VD and the ISE) and interaction effects (VD $\times$ ISE). Then, simple effects analysis was carried out on the neural emotional indicators with significant interaction effects. SPSS 22.0 (v22.0, SPSS Inc., Chicago, IL, USA) was used for the analysis. Origin9 (Origin Lab Inc., Northampton, MA, USA) was used to plot the analysis results. The study was approved by the ethical review board of Sichuan Agricultural University (No. 20210153). 


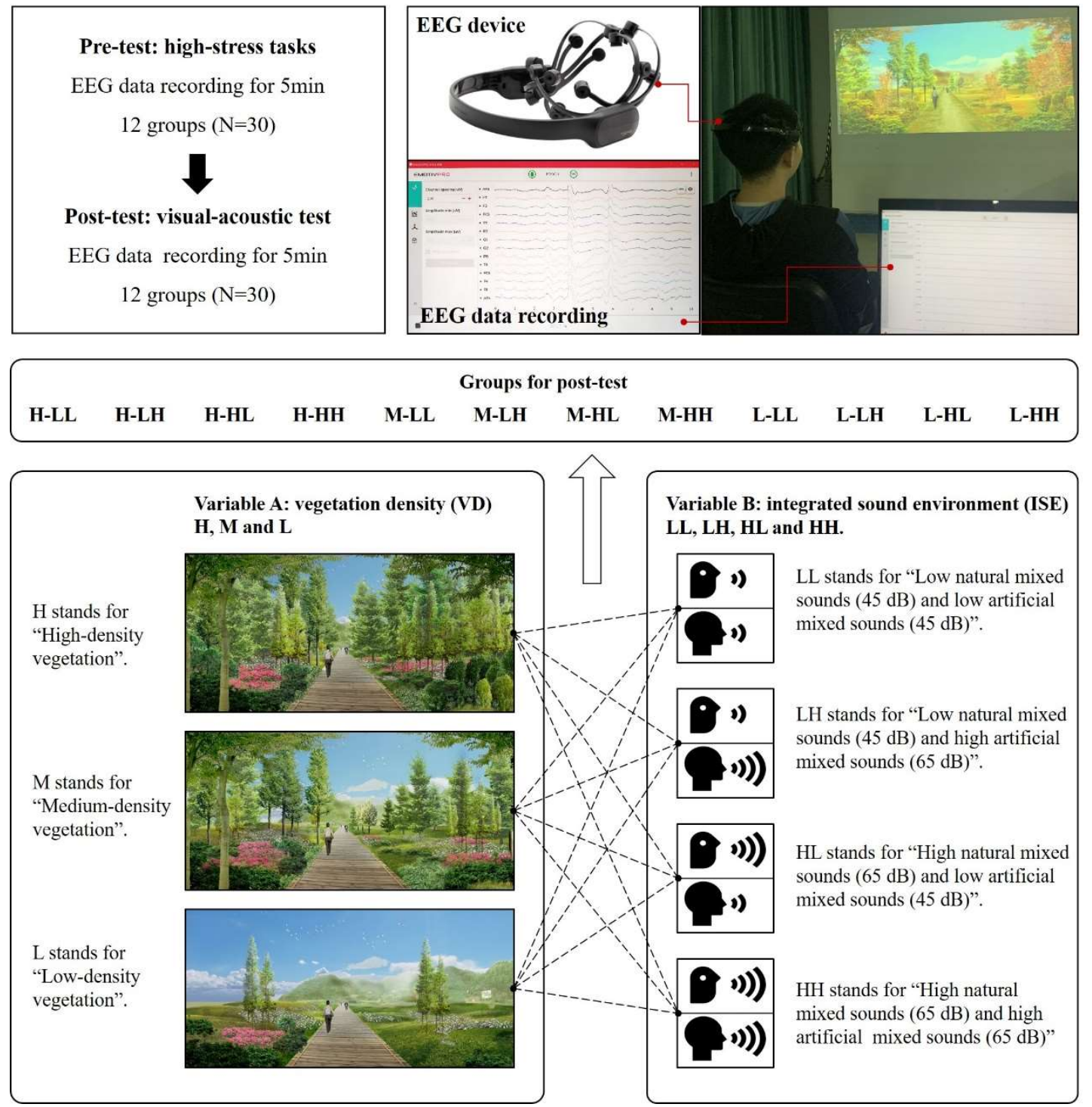

Figure 1. Procedure.

\section{Results}

\subsection{Analysis of the Main Effects on the Neural Emotional Parameter Values}

This study analyzed the main effects of the VD and the ISE on six neural emotional indicators (engagement, excitement, focus, interest, relaxation and stress) (Table A1) (Figure 2). The results show that there was a significant difference in these influences on the indicator of engagement. The main effects on engagement were not significant, and the interaction effect was not significant either. The values corresponding to excitement during the pretest and posttest were significantly different, and excitement was mainly reduced during the experiment. The main effect of the ISE was significant. The results show the following: LH $(\mathrm{M}=0.362)>\mathrm{LL}(\mathrm{M}=0.350)>\mathrm{HH}(\mathrm{M}=0.347)>\mathrm{HL}(\mathrm{M}=0.268)$. There was a significant difference in the influences of VD and ISE on the indicator of focus. The main effects of VD were significant. The corresponding results were as follows: $\mathrm{L}(\mathrm{M}=0.412)>\mathrm{H}(\mathrm{M}=0.379)$ $>\mathrm{M}(\mathrm{M}=0.367)$. The effect of ISE was thus significant, and the results were as follows: LH $(\mathrm{M}=0.426)>\mathrm{HH}(\mathrm{M}=0.409)>\mathrm{HL}(\mathrm{M}=0.369)>\mathrm{LL}(\mathrm{M}=0.341)$. In this case, the interaction effect was not significant. The difference in the effects of the VD and the ISE on the indicator of interest was significant, but the main effects were not significant. Additionally, the interaction effect was not significant. The difference in relaxation from the pretest and posttest was significant and decreased during the experiment. The main effect of the ISE was 
significant (Figure 2), and the results are as follows: $\mathrm{LL}(\mathrm{M}=0.276)>\mathrm{HL}(\mathrm{M}=0.266)>\mathrm{HH}$ $(M=0.239)>\mathrm{LH}(\mathrm{M}=0.219)$. The interaction effect was not significant. The difference in the stress from the pretest and posttest was significant and mainly decreased during the experiment. The main effect of VD was significant: $L(M=0.391)>H(M=0.374)$. The interaction effect was not significant.

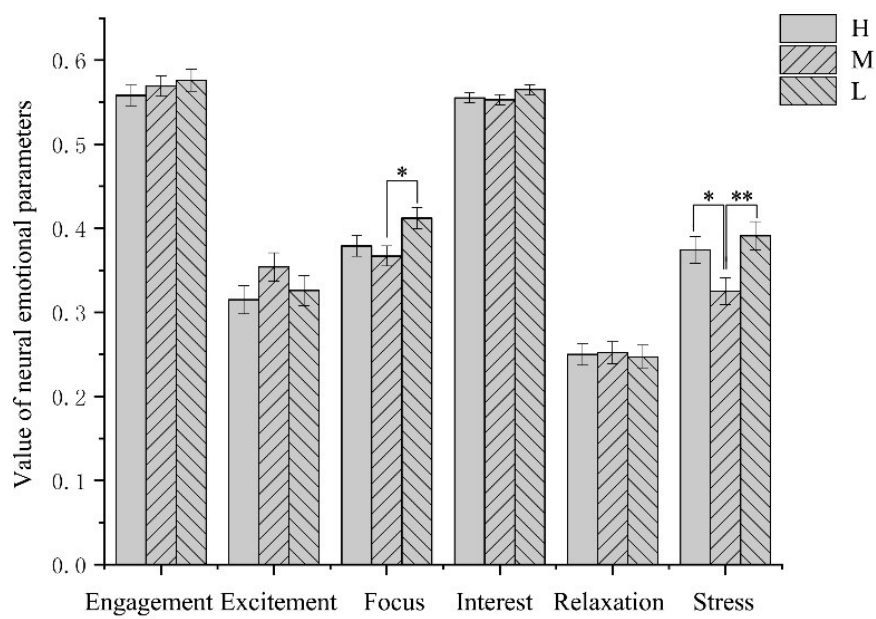

(a) Main effect of VD

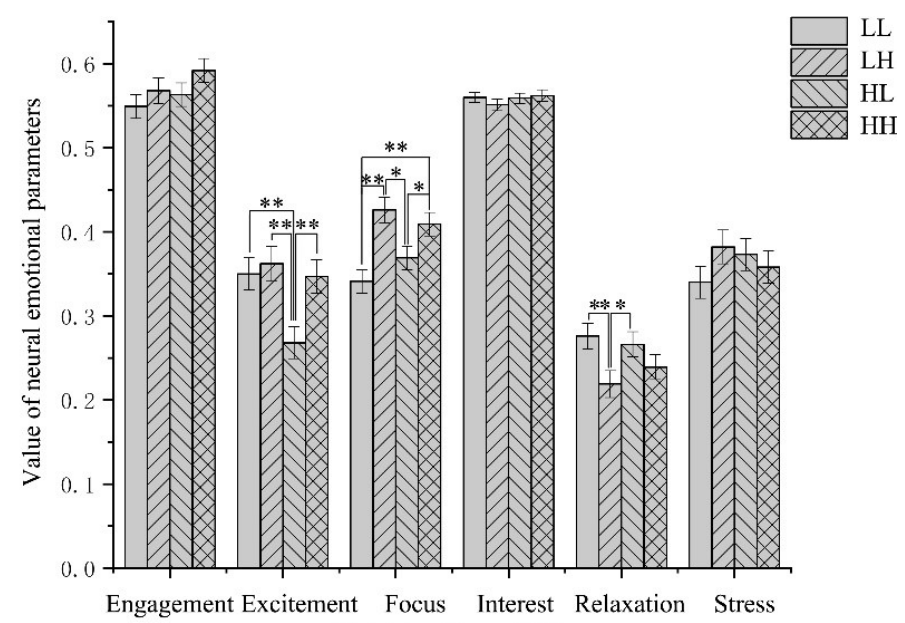

(b) Main effect of ISE

Figure 2. Values of neural emotional parameters in the main effects analysis $\left(\mathrm{N}=30\right.$; mean \pm standard error; ${ }^{*} p<0.05$; ** $p<0.01)$.

\subsection{Simple Effects Analysis of the Significant Interaction Effect of Neural Emotional}

Regarding the index of excitement, the primary effect analysis shows a significant difference in excitement from the pretest to the posttest, with a decrease. The main effect of the ISE was significant, which proves that the ISE may influence the variation in this index. However, due to the significant interaction effect, further interpretation should include the interaction effect, and the main effect should not be interpreted in isolation. The results of simple effects are as follows: H-LH $(\mathrm{M}=0.370)>\mathrm{H}-\mathrm{HL}(\mathrm{M}=0.224)$, and $\mathrm{H}-\mathrm{HH}(\mathrm{M}=0.359)$ $>\mathrm{H}-\mathrm{HL}(\mathrm{M}=0.224) ; \mathrm{M}-\mathrm{LL}(\mathrm{M}=0.400)>\mathrm{M}-\mathrm{HL}(\mathrm{M}=0.252)$, and $\mathrm{M}-\mathrm{LH}(\mathrm{M}=0.437)>\mathrm{M}-\mathrm{HL}$ $(\mathrm{M}=0.252) ; \mathrm{M}-\mathrm{LH}(\mathrm{M}=0.437)>\mathrm{L}-\mathrm{LH}(\mathrm{M}=0.278)$. The simple effects analysis further showed the significant interaction effect in the H-LH case, which was greater than the interaction effect in the H-HL case; the interaction effect for the M-LH case was higher than that in the M-HL case. When the VD was not low, with high-decibel artificial sound, the combined effect of the VD and the ISE was relatively high. In other words, in moderate- and high-VD spaces, the artificial tone level may have a certain positive effect on excitement, where a high level of VD is more likely to increase excitatory neural emotional expression (Figure 3) (Table A2).
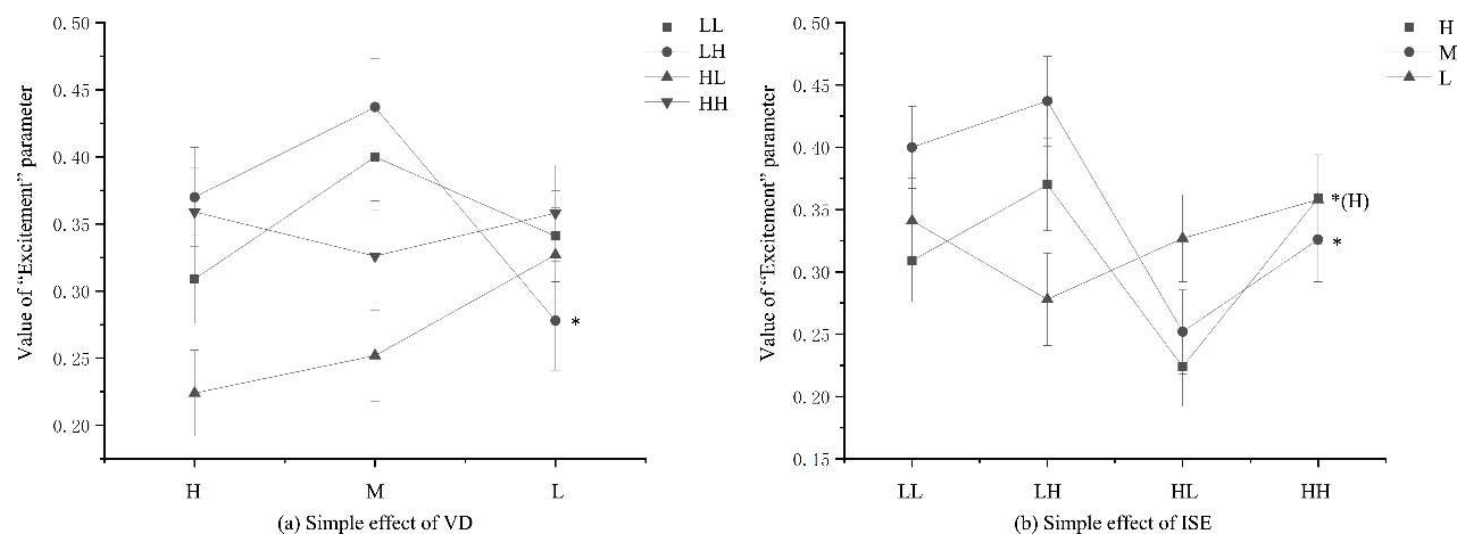

Figure 3. Values of the excitement parameter in the simple effect analysis $\left(N=30\right.$; mean \pm standard error; $\left.{ }^{*} p<0.05\right)$. 


\section{Discussion}

Interest in the connection between green space and human health is increasing among studies [50-53], and most results are discussed from the perspective of landscape ecology, such as the green space support diversity of wildlife habitats [54], or focus on people's preference for green space types (natural and artificial) [55]. Many studies assess the positive health effects of biogenic volatile organic compounds (BVOCs), microclimate and negative oxygen ion concentration in green space environments [56]. There are few studies on the structure of green spaces, especially VD, and even fewer studies on the effect of the density of green space density on human health and mental health. More importantly, the effects of the VD and the ISE on neural emotions have not been reported.

This study had five key results. First, our study found that a higher level of VD was more likely to result in excitatory neural emotions. The main effect analysis showed that the main effect of the ISE was significant (Table A1), proving that sound could cause a difference in this index. However, due to the significant interaction effect, further interpretation should consider the interaction effect, and the main effect should not be interpreted in isolation (Figure 3). The excitement parameter values observed in the $\mathrm{H}-\mathrm{LH}$ and $\mathrm{H}-\mathrm{HH}$ cases were higher than that observed in the $\mathrm{H}-\mathrm{HL}$ case, and the parameter value observed in the M-LH case was also higher than that observed in the M-HL case (Figure 3). When the VD level was not low and the artificial sound was provided at a high decibel, the level of excitement was relatively high. In other words, in spaces with a moderate- and high-level of VD spaces, the artificial sound level may have a certain positive effect on excitement. This finding is consistent with previous research. Burgess $[27,28]$ found that a higher level of VD was often associated with a more positive physical and mental health in experimental and observational studies, and the higher the VD level was, the higher people's preference for green space. Misgav [57] showed that a high canopy coverage and a moderate level of V49D can increase the environmental preference of the public. Another study [58] showed that people rated landscapes with a high level of VD as higher than those with a low level VD. On the other hand, a higher VD was more likely to result in excitatory neural emotional expression. When the level of VD increased from $1.7 \%$ to $24 \%$, the effect of attention recovery increased accordingly [24]. A study by Jiang [59] showed that VD and environmental preference were generally linearly related; as the VD increased, environmental preference also increased. When the VD level was relatively low, environmental preference increased slightly and then tended to increase steadily with increasing VD. When the VD level was too high, the preference gradually decreased. This finding was consistent with the results of another study [26], which showed a secondary distribution of VD and recreational suitability. That study also showed that middle-aged participants expressed a stronger preference for a higher level of VD.

Second, we found that focused emotional expressions can be more easily realized in a space with continuous vegetation. Sullivan's research [60] suggested that people generally prefer landscapes with mature trees, but other researchers [61] found that people did not like overly wild vegetation landscapes. Another study [62] showed that in urban forest landscapes, wild shrubs with minimal human management were preferred. Our study found that the main effects of VD and the ISE were significant, proving that these two factors can control this index. Additionally, there was no significant interaction effect; thus the interaction effect could be interpreted separately from the main effect. Visually, low-VD and high-VD spaces have one thing in common, namely, the continuity of elements is high. The sky and grass in a low-VD space have the highest continuity, while the trees in the high-VD space have the highest continuity. However, in the moderate-VD space, various elements are mixed; thus, it is difficult to attract continuous attention to a certain element. High-decibel artificial sounds are more likely to attract attention, possibly because the recognition of artificial sounds is higher than that of low-decibel natural and artificial sounds, but it is difficult to induce higher tones.

Third, it was easier for the participants to relax with a lower level of artificial sound. The main effect of the ISE was significant, proving that sounds are associated with relax- 
ation, additionally, there was no significant interaction effect with VD, and so the interaction effect can be interpreted separately from the main effect. This is consistent with Jesper J. Alvarsson's [5] findings that recovery tends to be faster in environments with natural sound than in noisy environments. These results suggest that the sympathetic nervous system recovers faster in response to natural sounds. The recovery of sympathetic arousal is influenced by the type of sound. The recovery speed in an environment with natural sounds $(50 \mathrm{~dB})$ was faster than that in an environment with noise, including low-decibel artificial noise $(50 \mathrm{~dB})$ and environmental noise $(40 \mathrm{~dB})$. The mechanism behind this faster recovery may be related to positive emotions. The effect of the sound pressure level (SPL) can be seen in this difference between high noise and low noise, which is consistent with previous psychoacoustics studies [63] on large SPL differences (30 dB). The effect of the natural acoustic environment on stress recovery may be greater in leisure and rural areas outside of cities with longer exposure times and lower SPLs. The above results are consistent with attention restoration theory [7], confirming that the natural environment helps to restore the ability of directed attention, thereby reducing mental fatigue and achieving relaxation.

Fourth, among the images tested, the moderate-VD space corresponded to lower stress emotional expression. Under visual perception, both extremely low and extremely high levels of VD density resulted in a higher emotional performance of stress. A medium level of VD density has lower pressure values, and the moderate-VD space corresponded to lower stress emotional performance. This finding is consistent with the research results of previous studies [64] indicating that people prefer a moderate level of VD and obtain more psychological and physiological benefits from it. The results of another study on the VD and preference of urban green space also proved that spaces with moderate VD obtained the highest preference rating [26].

Fifth, relaxation may be negatively correlated with stress and concentration under the influence of ambient sound. Stress and relaxation represent a pair of emotional expressions with opposite meanings. Considering the main effect of the VD on relaxation and the main effect of the ISE on stress, although they were not significant, they showed basically (not completely) opposite results. Interestingly, the focus values and the relaxation values present opposite results in terms of the main effect of the ISE. This result also suggests that people prefer greater VD in urban environments, a view reflected in the theory of attention restoration. Regarding attention recovery, Kaplan [7] proposed the theory that people's ability to suppress distractions will decrease with VD (attention recovery theory, ART), which naturally helps to supplement directed attention over time. Ulrich [8] hypothesized that people psychologically and physiologically respond to natural landscapes in a positive manner compared to architectural spaces without vegetation. In previous studies, some scholars have explored the correlation between ART and stress reduction theory (SRT) pathways, and this study also seems to have some interesting results at the neural emotional level, that is, the two may be negatively correlated under the influence of environmental sounds.

\section{Limitations}

This study focused on the effects of the VD and the ISE on human neural emotional variables. The limitations of this study were as follows. First, VD was the only visual factor considered. In addition, vegetation structure, plant species and biodiversity have a certain influence on human neural emotions but were not discussed here. Second, the decibel level was the main auditory factor discussed. In addition, decibel level may have an impact on sound combination and sound frequency. Third, the picture materials were generated via computer, which may be different from the effect of real environment on neural emotions, and EEG is a research method that provides data at the millisecond level. The advantage of neural emotional research lies in the short period required for experimentation, but human emotions may fluctuate over a long period of time; therefore, long-term research is a research direction to be considered in the future. 


\section{Conclusions}

This study examined the differences in neural emotional responses under different combinations VD and the ISE in green space. The results showed that the high-VD space was more likely to result in the emotional expression of excitement, while the moderate-VD space was more likely to result in a decrease in stress. The higher the VD level was, the more isolated the space was perceived as being. Regarding the future use of green space, the possible artificial elements and sounds that can be used to create an appropriate space must be considered. For example, some activities that require crowd assembly make a certain demand on the atmosphere and should be set in high-VD spaces, where it is easier to obtain the emotional expression of excitement. Another result is that in a space with continuous vegetation, it is easier to obtain focused emotional expression. ART can be used to analyze several visual elements, of which continuity is an important factor. Focus tends to be a neutral indicator of emotion, and it changed only slightly during this experimental work. Regarding the future use of green space, VD should be consciously designed. For some activities that require concentration, such as meditation, spaces with single elements and continuous views (for example, an extremely high-VD pure forest or a very low-VD large lawn) can more easily induce the emotional expression of focus. Additionally, the lower the artificial sound decibel level is, the easier it is to relax. It was found that not all artificial sounds have a negative effect on people. Artificial sounds are more likely to improve focus if they are more recognizable, change in frequency more slowly and are not jarring. Unfortunately, in this study, no interaction effect was observed for focus. In some special forested health and recuperation areas, pedestrian traffic control and artificial elements are used to reduce artificial sounds and induce more relaxed emotional expression.

Author Contributions: C.Z.: Conceptualization, Methodology, Writing-Original Draft, Project Administration. W.L. (Wei Lin): Conceptualization, Methodology, Writing-Review \& Editing, Software. N.L.: Writing-Review \& Editing, Resources. Y.W. (Ya Wen): Investigation, Data Curation. Y.W. (Yanxin Wang): Investigation, Data Curation. W.J.: Validation, Software. J.Z.: Investigation. H.Z.: Investigation. X.C.: Investigation. W.L. (Wenhao Luo): Investigation. Q.C.: Conceptualization, Methodology, Resources. All authors have read and agreed to the published version of the manuscript.

Funding: This research was funded by the Sichuan Provincial Science and Technology Department Science and Technology Project "Introduction and demonstration of key technologies in national park planning and design in the United States" (No. 2020ZHYZ0004).

Institutional Review Board Statement: The study was conducted according to the guidelines of the Declaration of Helsinki, and approved by the Institutional Review Board of Sichuan Agricultural University (No. 20210153).

Informed Consent Statement: Informed consent was obtained from all subjects involved in the study. Written informed consent has been obtained from the patient(s) to publish this paper.

Acknowledgments: This work was supported by the Sichuan Provincial Science and Technology Department Science and Technology Project "Introduction and demonstration of key technologies in national park planning and design in the United States" (No. 2020ZHYZ0004). This study was conducted after receiving approval from the Sichuan Agricultural University Institutional Animal Care and Use Committee (No. 20210153).

Conflicts of Interest: The authors declare no conflict of interest. 


\section{Appendix A}

Table A1. Main effects and interaction effects of VD and the ISE on the neural emotional parameters across the experimental groups (covariate: pretest; dependent variable: posttest).

\begin{tabular}{|c|c|c|c|c|c|c|c|}
\hline Parameters & $\begin{array}{l}\text { Sum of } \\
\text { Squares }\end{array}$ & df & $\begin{array}{l}\text { Mean } \\
\text { Square }\end{array}$ & $\mathbf{F}$ & Sig. & Partial $\eta^{2}$ & $\begin{array}{c}\text { Pairwise } \\
\text { Comparisons }\end{array}$ \\
\hline \multicolumn{8}{|l|}{ Engagement } \\
\hline VD × ISE & 0.113 & 6 & 0.019 & 1.209 & 0.301 & 0.024 & \\
\hline VD & 0.017 & 2 & 0.008 & 0.533 & 0.588 & 0.004 & \\
\hline ISE & 0.075 & 3 & 0.025 & 1.608 & 0.187 & 0.016 & \\
\hline Pretest & 1.127 & 1 & 1.127 & 72.165 & $0.000 * *$ & 0.196 & \\
\hline Error & 4.622 & 296 & 0.016 & & & & \\
\hline \multicolumn{8}{|l|}{$R^{2}=0.218\left(\operatorname{Adj} R^{2}=0.186\right)$} \\
\hline \multicolumn{8}{|l|}{ Excitement } \\
\hline $\mathrm{VD} \times \mathrm{ISE}$ & 0.497 & 6 & 0.083 & 2.716 & 0.014 * & 0.052 & \\
\hline VD & 0.082 & 2 & 0.041 & 1.342 & 0.263 & 0.009 & \\
\hline ISE & 0.434 & 3 & 0.145 & 4.743 & $0.003^{* *}$ & 0.046 & $\mathrm{LH}>\mathrm{LL}>\mathrm{HH}>\mathrm{HL}$ \\
\hline Pretest & 4.245 & 1 & 4.245 & 139.279 & $0.000 * *$ & 0.320 & \\
\hline Error & 9.021 & 296 & 0.030 & & & & \\
\hline \multicolumn{8}{|l|}{$R^{2}=0.399\left(\operatorname{Adj} R^{2}=0.375\right)$} \\
\hline \multicolumn{8}{|l|}{ Focus } \\
\hline $\mathrm{VD} \times \mathrm{ISE}$ & 0.129 & 6 & 0.022 & 1.402 & 0.214 & 0.028 & \\
\hline VD & 0.105 & 2 & 0.053 & 3.426 & 0.034 * & 0.023 & $\mathrm{~L}>\mathrm{H}>\mathrm{M}$ \\
\hline ISE & 0.332 & 3 & 0.111 & 7.197 & $0.000 * *$ & 0.068 & $\mathrm{LH}>\mathrm{HH}>\mathrm{HL}>\mathrm{LL}$ \\
\hline Pretest & 0.733 & 1 & 0.733 & 47.658 & $0.000 * *$ & 0.139 & \\
\hline Error & 4.551 & 296 & 0.015 & & & & \\
\hline \multicolumn{8}{|l|}{$R^{2}=0.284\left(\operatorname{Adj} R^{2}=0.254\right)$} \\
\hline \multicolumn{8}{|l|}{ Interest } \\
\hline $\mathrm{VD} \times \mathrm{ISE}$ & 0.004 & 6 & 0.001 & 0.183 & 0.981 & 0.004 & \\
\hline VD & 0.008 & 2 & 0.004 & 1.256 & 0.286 & 0.008 & \\
\hline ISE & 0.005 & 3 & 0.002 & 0.495 & 0.686 & 0.005 & \\
\hline Pretest & 0.534 & 1 & 0.534 & 161.745 & $0.000 * *$ & 0.353 & \\
\hline Error & 0.978 & 296 & 0.003 & & & & \\
\hline \multicolumn{8}{|l|}{$R^{2}=0.368\left(\operatorname{Adj} R^{2}=0.342\right)$} \\
\hline \multicolumn{8}{|l|}{ Relaxation } \\
\hline $\mathrm{VD} \times \mathrm{ISE}$ & 0.145 & 6 & 0.024 & 1.354 & 0.233 & 0.027 & \\
\hline VD & 0.001 & 2 & 0.001 & 0.031 & 0.969 & 0.000 & \\
\hline ISE & 0.147 & 3 & 0.049 & 2.746 & 0.043 * & 0.027 & $\mathrm{LL}>\mathrm{HL}>\mathrm{HH}>\mathrm{LH}$ \\
\hline Pretest & 3.038 & 1 & 3.038 & 170.218 & $0.000 * *$ & 0.365 & \\
\hline Error & 5.283 & 296 & 0.018 & & & & \\
\hline \multicolumn{8}{|l|}{$R^{2}=0.393\left(\operatorname{Adj} R^{2}=0.368\right)$} \\
\hline \multicolumn{8}{|l|}{ Stress } \\
\hline $\mathrm{VD} \times \mathrm{ISE}$ & 0.074 & 6 & 0.012 & 0.437 & 0.854 & 0.009 & \\
\hline VD & 0.239 & 2 & 0.119 & 4.235 & $0.015 *$ & 0.028 & $\mathrm{~L}>\mathrm{H}>\mathrm{M}$ \\
\hline ISE & 0.078 & 3 & 0.026 & 0.928 & 0.428 & 0.009 & \\
\hline Pretest & 2.231 & 1 & 2.231 & 79.195 & $0.000 * *$ & 0.211 & \\
\hline Error & 8.339 & 296 & 0.028 & & & & \\
\hline$R^{2}=0.280\left(\operatorname{Adj} R^{2}=0.251\right)$ & & & & & & & \\
\hline
\end{tabular}

Note: VD means vegetation density. ISE means integrated sound environment. H means high-density vegetation. M means moderatedensity vegetation. $L$ means low-density vegetation. LL means low-decibel artificial sounds $(45 \mathrm{~dB})$ and low natural mixed sounds $(45 \mathrm{~dB})$. LH means low-decibel artificial sounds ( $45 \mathrm{~dB}$ ) and high natural mixed sounds ( $65 \mathrm{~dB})$. HL means high-decibel artificial sounds ( $65 \mathrm{~dB})$ and low natural mixed sounds $(45 \mathrm{~dB})$. HH means high-decibel artificial sounds $(65 \mathrm{~dB})$ and high natural mixed sounds $(65 \mathrm{~dB}) .{ }^{*} p<0.05$; ** $p<0.01$. 
Table A2. Simple effects analysis of the parameters that have significant interaction effects $(\mathrm{VD} \times$ ISE) and significant preand posttest differences.

\begin{tabular}{|c|c|c|c|c|c|c|c|}
\hline Parameters & $\begin{array}{l}\text { Sum of } \\
\text { Squares }\end{array}$ & $\mathrm{df}$ & $\begin{array}{l}\text { Mean } \\
\text { Square }\end{array}$ & $\mathbf{F}$ & Sig. & Partial $\eta^{2}$ & $\begin{array}{c}\text { Pairwise } \\
\text { Comparisons }\end{array}$ \\
\hline \multicolumn{8}{|l|}{ Excitement } \\
\hline ISE $(\mathrm{VD}=\mathrm{H})$ & 0.356 & 3 & 0.119 & 3.889 & $0.009 *$ & 0.038 & $\mathrm{LH}>\mathrm{HL}, \mathrm{HH}>\mathrm{HL}$ \\
\hline Error & 9.021 & 296 & 0.030 & & & & \\
\hline ISE (VD = M) & 0.525 & 3 & 0.175 & 5.745 & $0.001 *$ & 0.055 & $\mathrm{LL}>\mathrm{HL}, \mathrm{LH}>\mathrm{HL}$ \\
\hline Error & 9.021 & 296 & 0.030 & & & & \\
\hline ISE (VD = L) & 0.080 & 3 & 0.027 & 0.871 & 0.456 & 0.009 & \\
\hline Error & 9.021 & 296 & 0.030 & & & & \\
\hline VD (ISE = LL) & 0.121 & 2 & 0.061 & 1.993 & 0.138 & 0.013 & \\
\hline Error & 9.021 & 296 & 0.030 & & & & \\
\hline VD (ISE = LH) & 0.291 & 2 & 0.146 & 4.779 & $0.009 *$ & 0.031 & $M>L$ \\
\hline Error & 9.021 & 296 & 0.030 & & & & \\
\hline VD (ISE = HL) & 0.148 & 2 & 0.074 & 2.434 & 0.089 & 0.016 & \\
\hline Error & 9.021 & 296 & 0.030 & & & & \\
\hline VD $(\mathrm{ISE}=\mathrm{HH})$ & 0.018 & 2 & 0.009 & 0.287 & 0.751 & 0.002 & \\
\hline Error & 9.021 & 296 & 0.030 & & & & \\
\hline
\end{tabular}

Note: VD means vegetation density. ISE means integrated sound environment. H means high-density vegetation. M means moderatedensity vegetation. L means low-density vegetation. LL means low-decibel artificial sounds (45 dB) and low natural mixed sounds (45 dB). LH means low-decibel artificial sounds $(45 \mathrm{~dB})$ and high natural mixed sounds $(65 \mathrm{~dB})$. HL means high-decibel artificial sounds $(65 \mathrm{~dB})$ and low natural mixed sounds $(45 \mathrm{~dB})$. HH means high-decibel artificial sounds $(65 \mathrm{~dB})$ and high natural mixed sounds $(65 \mathrm{~dB}) .{ }^{*} p<0.05$.

\section{References}

1. Hunter, R.F.; Cleland, C.; Cleary, A.; Droomers, M.; Wheeler, B.W.; Sinnett, D.; Nieuwenhuijsen, M.J.; Braubach, M. Environmental, health, wellbeing, social and equity effects of urban green space interventions: A meta-narrative evidence synthesis. Environ. Int. 2019, 130, 104923. [CrossRef] [PubMed]

2. Gore, F.M.; Bloem, P.J.; Patton, G.C.; Ferguson, J.; Joseph, V.; Coffey, C.; Sawyer, S.M.; Mathers, C.D. Global burden of disease in young people aged 10-24 years: A systematic analysis. Lancet 2011, 377, 2093-2102. [CrossRef]

3. Alarcao, S.M.; Fonseca, M.J. Emotions Recognition Using EEG Signals: A Survey. IEEE Trans. Affect. Comput. 2017, 10, 374-393. [CrossRef]

4. Houlden, V.; Weich, S.; De Albuquerque, J.P.; Jarvis, S.; Rees, K. The relationship between greenspace and the mental wellbeing of adults: A systematic review. PLoS ONE 2018, 13, e0203000. [CrossRef]

5. Alvarsson, J.J.; Wiens, S.; Nilsson, M. Stress Recovery during Exposure to Nature Sound and Environmental Noise. Int. J. Environ. Res. Public Health 2010, 7, 1036-1046. [CrossRef]

6. Hartig, T.; van den Berg, A.E.; Hagerhall, C.M.; Tomalak, M.; Bauer, N.; Hansmann, R.; Ojala, A.; Syngollitou, E.; Carrus, G.; van Herzele, A. Health benefits of nature experience: Psychological, social and cultural processes. In Forests, Trees and Human Health; Springer: Dordrecht, The Netherlands, 2011; pp. 127-168.

7. Kaplan, S. The restorative benefits of nature: Toward an integrative framework. J. Environ. Psychol. 1995, 15, 169-182. [CrossRef]

8. Ulrich, R.S.; Simons, R.F.; Losito, B.D.; Fiorito, E.; Miles, M.A.; Zelson, M. Stress recovery during exposure to natural and urban environments. J. Environ. Psychol. 1991, 11, 201-230. [CrossRef]

9. Velarde, M.; Fry, G.; Tveit, M. Health effects of viewing landscapes—Landscape types in environmental psychology. Urban For. Urban Green. 2007, 6, 199-212. [CrossRef]

10. Vujcic, M.; Tomicevic-Dubljevic, J.; Grbic, M.; Lecic-Tosevski, D.; Vukovic, O.; Toskovic, O. Nature based solution for improving mental health and well-being in urban areas. Environ. Res. 2017, 158, 385-392. [CrossRef] [PubMed]

11. Elsadek, M.; Liu, B.; Lian, Z. Green façades: Their contribution to stress recovery and well-being in high-density cities. Urban For. Urban Green. 2019, 46, 126446. [CrossRef]

12. Aspinall, P.; Mavros, P.; Coyne, R.; Roe, J. The urban brain: Analysing outdoor physical activity with mobile EEG. Br. J. Sports Med. 2015, 49, 272-276. [CrossRef]

13. Ulrich, R.S.; Zimring, C.; Zhu, X.; DuBose, J.; Seo, H.B.; Choi, Y.S.; Yuan, X.; Joseph, A. A review of the research literature on evidence-based healthcare design. HERD Health Environ. Res. Des. J. 2008, 1, 61-125. [CrossRef]

14. Hartig, T.; Mitchell, R.; De Vries, S.; Frumkin, H. Nature and health. Annu. Rev. Public Health 2014, 35, 207-228. [CrossRef] [PubMed]

15. Raheel, A.; Majid, M.; Anwar, S.M.; Bagci, U. Emotion classification in response to tactile enhanced multimedia using frequency domain features of brain signals. In Proceedings of the 2019 41st Annual International Conference of the IEEE Engineering in Medicine and Biology Society (EMBC), Berlin, Germany, 23-27 July 2019; pp. 1201-1204. 
16. Suhaimi, N.S.; Mountstephens, J.; Teo, J. EEG-Based Emotion Recognition: A State-of-the-Art Review of Current Trends and Opportunities. Comput. Intell. Neurosci. 2020, 2020, 1-19. [CrossRef]

17. Partala, T.; Jokinierni, M.; Surakka, V. Pupillary responses to emotionally provocative stimuli. In Proceedings of the 2000 Symposium on Eye Tracking Research \& Applications, Palm Beach Gardens, FL, USA, 6-8 November 2000; pp. 123-129.

18. Lin, W.; Chen, Q.; Jiang, M.; Tao, J.; Liu, Z.; Zhang, X.; Wu, L.; Xu, S.; Kang, Y.; Zeng, Q. Sitting or Walking? Analyzing the Neural Emotional Indicators of Urban Green Space Behavior with Mobile EEG. J. Hered. 2020, 97, 191-203. [CrossRef] [PubMed]

19. Jenke, R.; Peer, A.; Buss, M. Feature Extraction and Selection for Emotion Recognition from EEG. IEEE Trans. Affect. Comput. 2014, 5, 327-339. [CrossRef]

20. Ahern, G.L.; Schwartz, G.E. Differential lateralization for positive and negative emotion in the human brain: EEG spectral analysis. Neuropsychologia 1985, 23, 745-755. [CrossRef]

21. Chang, C.-Y.; Hammitt, W.E.; Chen, P.-K.; Machnik, L.; Su, W.-C. Psychophysiological responses and restorative values of natural environments in Taiwan. Landsc. Urban Plan. 2008, 85, 79-84. [CrossRef]

22. Johansson, M.; Gyllin, M.; Witzell, J.; Küller, M. Does biological quality matter? Direct and reflected appraisal of biodiversity in temperate deciduous broad-leaf forest. Urban For. Urban Green. 2014, 13, 28-37. [CrossRef]

23. Purcell, A.T.; Lam, R.J. Preference and naturalness: An ecological approach. Landsc. Urban Plan. 1998, 42, 57-66. [CrossRef]

24. Jiang, B.; Li, D.; Larsen, L.; Sullivan, W. A Dose-Response Curve Describing the Relationship between Urban Tree Cover Density and Self-Reported Stress Recovery. Environ. Behav. 2014, 48, 607-629. [CrossRef]

25. Grinde, B.; Patil, G.G. Biophilia: Does visual contact with nature impact on health and well-being? Int. J. Environ. Res. Public Health 2009, 6, 2332-2343. [CrossRef] [PubMed]

26. Bjerke, T.; Østdahl, T.; Thrane, C.; Strumse, E. Vegetation density of urban parks and perceived appropriateness for recreation. Urban For. Urban Green. 2006, 5, 35-44. [CrossRef]

27. Burgess, J.; Harrison, C.M.; Limb, M. People, Parks and the Urban Green: A Study of Popular Meanings and Values for Open Spaces in the City. Urban Stud. 2016, 25, 455-473. [CrossRef]

28. Madge, C. Public parks and the geography of fear. Tijdschr. Voor Econ. En Soc. Geogr. 1997, 88, 237-250. [CrossRef]

29. Gan, Y.; Luo, T.; Breitung, W.; Kang, J.; Zhang, T. Multi-sensory landscape assessment: The contribution of acoustic perception to landscape evaluation. J. Acoust. Soc. Am. 2014, 136, 3200-3210. [CrossRef]

30. Hong, J.Y.; Ong, Z.-T.; Lam, B.; Ooi, K.; Gan, W.-S.; Kang, J.; Feng, J.; Tan, S.-T. Effects of adding natural sounds to urban noises on the perceived loudness of noise and soundscape quality. Sci. Total Environ. 2019, 711, 134571. [CrossRef]

31. Gidlöf-Gunnarsson, A.; Öhrström, E. Noise and well-being in urban residential environments: The potential role of perceived availability to nearby green areas. Landsc. Urban Plan. 2007, 83, 115-126. [CrossRef]

32. Aletta, F.; Kang, J.; Axelsson, Ö. Soundscape descriptors and a conceptual framework for developing predictive soundscape models. Landsc. Urban Plan. 2016, 149, 65-74. [CrossRef]

33. Viollon, S.; Lavandier, C.; Drake, C. Influence of visual setting on sound ratings in an urban environment. Appl. Acoust. 2002, 63, 493-511. [CrossRef]

34. Lindquist, M.; Maxim, B.; Proctor, J.; Dolins, F. The effect of audio fidelity and virtual reality on the perception of virtual greenspace. Landsc. Urban Plan. 2020, 202, 103884. [CrossRef]

35. Miller, N.P. US National Parks and management of park soundscapes: A review. Appl. Acoust. 2008, 69, 77-92. [CrossRef]

36. Weinzimmer, D.; Newman, P.; Taff, D.; Benfield, J.; Lynch, E.; Bell, P. Human Responses to Simulated Motorized Noise in National Parks. Leis. Sci. 2014, 36, 251-267. [CrossRef]

37. Pilcher, E.J.; Newman, P.; Manning, R.E. Understanding and Managing Experiential Aspects of Soundscapes at Muir Woods National Monument. Environ. Manag. 2009, 43, 425-435. [CrossRef]

38. Watts, G.R.; Pheasant, R.J. Tranquillity in the Scottish Highlands and Dartmoor National Park-The importance of soundscapes and emotional factors. Appl. Acoust. 2015, 89, 297-305. [CrossRef]

39. Anderson, L.M.; Mulligan, B.E.; Goodman, L.S.; Regen, H.Z. Effects of Sounds on Preferences for Outdoor Settings. Environ. Behav. 1983, 15, 539-566. [CrossRef]

40. Ge, J.; Hokao, K. Applying the methods of image evaluation and spatial analysis to study the sound environment of urban street areas. J. Environ. Psychol. 2005, 25, 455-466. [CrossRef]

41. Hong, J.; Jeon, J.Y. Designing sound and visual components for enhancement of urban soundscapes. J. Acoust. Soc. Am. 2013, 134, 2026-2036. [CrossRef]

42. Maffei, L.; Masullo, M.; Aletta, F.; Di Gabriele, M. The influence of visual characteristics of barriers on railway noise perception. Sci. Total Environ. 2013, 445-446, 41-47. [CrossRef]

43. Jo, H.I.; Jeon, J.Y. The influence of human behavioral characteristics on soundscape perception in urban parks: Subjective and observational approaches. Landsc. Urban Plan. 2020, 203, 103890. [CrossRef]

44. Neale, C.; Aspinall, P.; Roe, J.; Tilley, S.; Mavros, P.; Cinderby, S.; Coyne, R.; Thin, N.; Bennett, G.; Thompson, C.W. The Aging Urban Brain: Analyzing Outdoor Physical Activity Using the Emotiv Affectiv Suite in Older People. J. Hered. 2017, 94, 869-880.

45. Barham, M.P.; Clark, G.M.; Hayden, M.J.; Enticott, P.G.; Conduit, R.; Lum, J.A. Acquiring research-grade ERPs on a shoestring budget: A comparison of a modified Emotiv and commercial SynAmps EEG system. Psychophysiology 2017, 54, 1393-1404. [CrossRef] [PubMed] 
46. Debener, S.; Minow, F.; Emkes, R.; Gandras, K.; De Vos, M. How about taking a low-cost, small, and wireless EEG for a walk? Psychophysiology 2012, 49, 1617-1621. [CrossRef] [PubMed]

47. Cahn, D.A.; Salmon, D.P.; Butters, N.; Wiederholt, W.C.; Corey-Bloom, J.; Edelstein, S.L.; Barrett-Connor, E. Detection of dementia of the Alzheimer type in a population-based sample: Neuropsychological test performance. J. Int. Neuropsychol. Soc. 1995, 1, 252-260. [CrossRef] [PubMed]

48. Chiang, Y.-C.; Li, D.; Jane, H.-A. Wild or tended nature? The effects of landscape location and vegetation density on physiological and psychological responses. Landsc. Urban Plan. 2017, 167, 72-83. [CrossRef]

49. Gotts, Z.M.; Ellis, J.; Deary, V.; Barclay, N.; Newton, J.L. The Association between Daytime Napping and Cognitive Functioning in Chronic Fatigue Syndrome. PLoS ONE 2015, 10, e0117136. [CrossRef]

50. de Brito, J.N.; Pope, Z.C.; Mitchell, N.R.; Schneider, I.E.; Larson, J.M.; Horton, T.H.; Pereira, M.A. The effect of green walking on heart rate variability: A pilot crossover study. Environ. Res. 2020, 185, 109408. [CrossRef]

51. Labib, S.; Lindley, S.; Huck, J.J. Spatial dimensions of the influence of urban green-blue spaces on human health: A systematic review. Environ. Res. 2020, 180, 108869. [CrossRef]

52. Markevych, I.; Schoierer, J.; Hartig, T.; Chudnovsky, A.; Hystad, P.; Dzhambov, A.; de Vries, S.; Triguero-Mas, M.; Brauer, M.; Nieuwenhuijsen, M.; et al. Exploring pathways linking greenspace to health: Theoretical and methodological guidance. Environ. Res. 2017, 158, 301-317. [CrossRef]

53. Pearsall, H.; Eller, J.K. Locating the green space paradox: A study of gentrification and public green space accessibility in Philadelphia, Pennsylvania. Landsc. Urban Plan. 2020, 195, 103708. [CrossRef]

54. Parsons, R. Conflict between ecological sustainability and environmental aesthetics—Conundrum, canard or curiosity. Landsc. Urban Plan. 1995, 32, 227-244. [CrossRef]

55. De Groot, W.T.; van den Born, R.J.G. Visions of nature and the landscape type preferences: An exploration in the Netherlands. Landsc. Urban Plan. 2003, 63, 127-138. [CrossRef]

56. Bach Pages, A.; Peñuelas, J.; Clarà, J.; Llusià, J.; Campillo i López, F.; Maneja, R. How should forests be characterized in regard to human health? Evidence from existing literature. Int. J. Environ. Res. Public Health 2020, 17, 1027. [CrossRef]

57. Misgav, A. Visual preference of the public for vegetation groups in Israel. Landsc. Urban Plan. 2000, 48, 143-159. [CrossRef]

58. De Val, G.D.L.F.; Mühlhauser, H. Visual quality: An examination of a South American Mediterranean landscape, Andean foothills east of Santiago (Chile). Urban For. Urban Green. 2014, 13, 261-271. [CrossRef]

59. Jiang, B.; Larsen, L.; Deal, B.; Sullivan, W.C. A dose-response curve describing the relationship between tree cover density and landscape preference. Landsc. Urban Plan. 2015, 139, 16-25. [CrossRef]

60. Lovell, S.T.; Sullivan, W.C. Environmental benefits of conservation buffers in the United States: Evidence, promise, and open questions. Agric. Ecosyst. Environ. 2006, 112, 249-260. [CrossRef]

61. Nassauer, J.I. Messy ecosystems, orderly frames. Landsc. J. 1995, 14, 161-170. [CrossRef]

62. Tyrväinen, L.; Silvennoinen, H.; Kolehmainen, O. Ecological and aesthetic values in urban forest management. Urban For. Urban Green. 2003, 1, 135-149. [CrossRef]

63. Lusk, S.L.; Gillespie, B.; Hagerty, B.M.; Ziemba, R.A. Acute Effects of Noise on Blood Pressure and Heart Rate. Arch. Environ. Health Int. J. 2004, 59, 392-399. [CrossRef] [PubMed]

64. Jiang, B.; Li, D.; Larsen, L.; Sullivan, W.C. A dose-response curve describing the relationship between urban tree cover density and self-reported stress recovery. Environ. Behav. 2016, 48, 607-629. [CrossRef] 